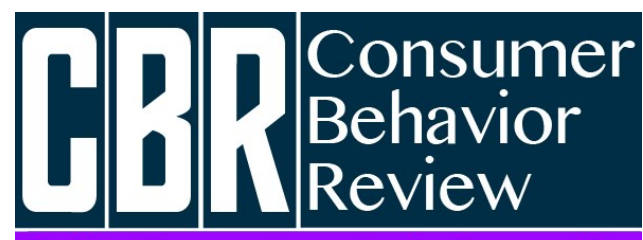

Revista Comportamento do Consumidor
Broeder, P., \& Schouten, M. (2022). The Impact of Product Tagging on Trust and Purchase Intention: A cross-cultural perspective in visual e-commerce. Consumer Behavior Review, 6(1), e-250595.
ISSN: 2526-7884

Editor: Prof. Dr. Marconi Freitas da Costa

E-mail: cbr@ufpe.br
Evaluation: Double blind review

Received: May 21, 2021

Approved: October 06, 2021

\title{
THE IMPACT OF PRODUCT TAGGING ON TRUST AND PURCHASE INTENTION: A CROSS-CULTURAL PERSPECTIVE IN VISUAL E-COMMERCE
}

\author{
O Impacto da Marcação de Produto na Confiança e na Intenção de Compra: Uma perspectiva
} intercultural no e-commerce visual

\author{
Peter Broeder ${ }^{1}$ \\ ORCID: http://orcid.org/0000-0001-6274-2040 \\ E-mail: peter@broeder.com \\ Michelle Schouten ${ }^{1}$ \\ ORCID: http://orcid.org/0000-0003-2282-605X \\ E-mail: mschouten94@gmail.com
}

${ }^{1}$ Tilburg University, Department of Communication and Cognition, Tilburg, Netherlands

\begin{abstract}
The present study aims to examine the opportunity of in-app shopping, more specifically, analyzing the influence of product tags and cultural background on consumers' trust and purchase intention. For this purpose, a comparison was made between European and South American female consumers from two cultures: the Netherlands and Paraguay. A total of 225 subjects, 143 from the Dutch background and 82 from the Paraguayan background, participated in an experimental survey where they judged an Instagram
\end{abstract}

\begin{abstract}
Resumo
0 presente estudo tem como objetivo examinar a oportunidade de compras no aplicativo, mais especificamente, analisando a influência das marcas do produto e da formação cultural na confiança e na intenção de compra dos consumidores. Para tanto, foi feita uma comparação entre consumidoras europeias e sul-americanas de duas culturas: Holanda e Paraguai. Um total de 225 indivíduos, 143 de origem holandesa e 82 de origem paraguaia, participaram de uma pesquisa experimental em que julgaram uma
\end{abstract}


product page (product tag: present vs. absent). The analysis of the results revealed that the Paraguayans had higher purchase intentions than the Dutch. Additionally, the presence of a text appeal in the visual product presentation had a direct positive effect on consumers' purchase intentions and perceived trust in the shopping environment, for both the Dutch and Paraguayan cultural groups. In virtual web shops, perceiving trust is a decisive point for purchase intentions. This study contributes to the fast-growing investigations on social media effectiveness and visual marketing as an informative and persuasive tool. The findings pinpoint the synergic value of visual and textual cues of product presentation online in the atmospheric trust of in-app shopping.

Keywords: Consumer behavior; Social commerce; Trust; Purchase intention; Crosscultural. página de produto do Instagram (tag do produto: presente vs. ausente). A análise dos resultados revelou que os paraguaios tinham maior intenção de compra do que os holandeses. Além disso, a presença de um apelo de texto na apresentação visual do produto teve um efeito positivo direto nas intenções de compra dos consumidores e na percepção de confiança no ambiente de compras, tanto para grupos culturais holandeses quanto paraguaios. Nas lojas virtuais da Web, perceber a confiança é um ponto decisivo para as intenções de compra. Este estudo contribui para o rápido crescimento das investigações sobre a eficácia da mídia social e o marketing visual como uma ferramenta informativa e persuasiva. As descobertas apontam o valor sinérgico das dicas visuais e textuais da apresentação do produto online na confiança atmosférica das compras no aplicativo.

Palavras-chave: Comportamento do consumidor; Comércio social; Confiar; Intenção de compra; Intercultural.

This work is licensed under a Creative Commons Attribution 4.0 International License: https://creativecommons.org/licenses/by/4.0/

\section{INTRODUCTION}

Online shoppers do not have the opportunity to directly examine, try, touch, or smell a product; therefore, detailed information about its characteristics and specifications gain special relevance. In this respect, through in-app shopping, e-commerce continues to evolve as social commerce, with the capacity to further consumer interactivity. Social media platforms, such as Facebook, Twitter, YouTube, and Instagram, have developed new features to facilitate online shopping; among them is Instagram's product tagging, which was introduced in 2018. This feature allows an online seller of a product to post a picture of their product along with its description, name, and price on Instagram. By clicking on the tag, a consumer is navigated to the product on the seller's web store without having to leave the social media platform. The Instagram environment creates enjoyment and contentment, and the trust in the social network platform is transferred to the online shopping process; Instagram's product-tagging feature reduces the uncertainty of consumers engaging in online purchases.

The importance of considering the effects of (digital) product presentation is broadly recognized in advertising and marketing communications. Advertising studies mostly focus on the optimal effects of visual features. Images are more emotionally evocative than words and directed to attract attention (Holmes \& Mathews, 2005). On the other hand, e-commerce studies underpin the superiority of the effects of verbal product information above visual product information (Rietveld et al., 2020). For social media, empirical findings of the investigation on modality effects on consumer behavior are, to some degree, mixed (Kim, 2019). There are two notable gaps germane to the present study.

The first gap is that systematic comparisons of the effects of visual and textual cues on consumer purchase intentions are scarce (Djafarova \& Bowes, 2021). Images are a distinctive characteristic of a lot of social media platforms. Remarkably, extant social media marketing studies predominantly dealt with the textual content (for example, the use of hashtags, blogs, tweets, or 
reviews) of user-generated content and, hereby, paid little attention to the visuals (Klostermann et al., 2018; Song et al., 2018). Several meta reviews concluded that more investigations should be done of the persuasive and engaging functions of visual cues (Babić Rosario et al., 2016), specifically in an Instagram context (De Oliveira Santini et al., 2020).

Similar to Hollebeek (2018), in their meta overview of factors that determine online consumer engagement, Vander Schee et al. (2020) point out the "virtual silence" of existing cultural and country level. Specifically, the second notable gap of investigations into product presentation of e-commerce studies is that culturally specific consumer preferences are hardly taken into account. Studies have shown that cultural background has an essential role in consumer behavior (De Mooij, 2019). Next to global preferences online, cultures develop local variations of social media use. Therefore, it is a reasonable conjecture that the effect of risk-reducing information in online purchases differs for consumers with culturally related differences in uncertainty avoidance (Mosunmola et al., 2019).

To fill these two gaps, this study investigates the effect of the presence of an Instagram shopping tag on consumers' trust and purchase intentions. Specifically, the focus is on the perceptions and preferences of consumers from Europe (the Netherlands) and South America (Paraguay) with a fictitious fashion-selling app on Instagram. By doing so, this study aims to contribute to the fastgrowing investigations on social media effectiveness and visual marketing as an informative and persuasive tool. The findings pinpoint the synergic value of visual and textual cues of product presentation online in the atmospheric trust of in-app shopping. Eventually, this study gives rise to the importance of considering local cultural-related consumer preference in the global ambiance of ecommerce.

The paper is organized as follows. First, the attraction of verbal and visual product cues is clarified and related to online consumer behavior (purchase intention). Culturally, the persuasive appeal of text vs. image is explained through the high-/low-context distinction theory of Hall (1976), which has been utilized extensively in a wide variety of cross-cultural investigations. Then the core notion of online trust is delineated and culturally differentiated by the dimension of uncertainty avoidance from Hofstede's (2001) model. This is followed by specifying the research context of the present study, specifically the visual Instagram platform that launched a new call-to-action shopping bag button equipping users with the ability to add text to the visual product presentation. To this end, an online experiment is introduced with a fictitious Instagram web store that has Dutch (the Netherlands) and Paraguayan participants. After a detailed account of the experiment's method, the findings are presented as they pertain to the perceptions and preferences of consumers with different cultural backgrounds. The paper ends by offering suggestions for theoretical and managerial implications.

\section{LITERATURE REVIEW}

\section{Visual and textual appeals in product presentation}

Generally, images and words provide different degrees of abstractions. In a product display, the visual presentation is concrete and intended to let the product look like it is in reality. The textual presentation complements the visual with detailed information that activates more abstract constructs. Words carry the essence of the displayed product by abstracting its basic characteristics, such as product category, brand, mention, price, or availability (Amit et al., 2012; Lee et al., 2018). Smith (1991) noticed that if verbal and visual sources disclose the same information (in printed advertisements for common products/services, such as a pizza delivery), there is higher uncertainty towards the visual information, because verbal information is more explicit and specific than visual images.

Kim and Lennon (2008) examined how different presentation formats in online shopping influenced consumers' attitudes and purchase intentions. They found that both visual and verbal information positively affect consumers' attitudes (for instance, attractiveness and perceived amount of information). However, in their study, there was a verbal priority effect on the intention to purchase an apparel item in a mock web store (Kim \& Lennon, 2008). Similar to Blanco et al. (2010), Kim (2019) identified the combination of visual and verbal stimuli, which helps best in facilitating and processing 
information, both discursive processing (such as verbal retrieval and encoding) as well as imaginary processing (involving more sensory experiences and concreteness). The newest insights are the outcomes of large-scale content analyses of huge databases consisting of actual user activity on social platforms. For example, Giannoulakis and Tsapatsoulis (2016) and Ha et al. (2021) explored the actual utilization of hashtags, text tags, and images on Instagram, In the same vein, Song et al. (2018) automatically detected user profile attributes such as age and gender. Their findings suggested that user profiling based on visual images outperforms classification models of textual tags. In addition, they noted that images act as an effective complement to textual tags.

Consumers process product information differently for the visual and textual modalities, as humans process visual information more rapidly than textual information. Correspondingly, visual appeals also have different persuasive effects on the consumer compared to textual appeals (Kim, 2019; Rietveld et al., 2020). However, it is highly likely that consumers from distinctively different cultures might perceive the evaluation of visual and text appeals of the very same product information differently. The idea is that the use of context for establishing information and meaning in communication (and our case a product presentation) varies across cultures.

In Hall's (1976) contexting theory, cultures can be characterized as primarily low- or highcontext cultures. In high-context cultures, the message is "one in which most of the information is either in the physical context or internalized in the person, while very little is in the coded, explicit, transmitted part of the message" (Hall, 1976, p. 91). The message's meaning can be established only through the minor (needed) activation of the context that consists of pre-programmed and culturespecific cues. The members of these cultures are used to implicit and indirect messages with symbolic and visual associations. In contrast, in low-context cultures, "the mass of the information is vested in the explicit code" (Hall, 1976, p. 91). The members of these cultures are used to direct and explicit messages (visually and verbally). They usually prefer low-context messages, and information is expressed largely through words. Hall's conceptualizing of cultural contexts was instanced by a limited list of countries, composing a continuum from primarily high-context cultures (such as Japan, China, and Arabic countries) to primarily low-context cultures (such as North America, Scandinavian, and German-speaking countries) (Hall, 1976; Hall \& Hall, 1990).

\section{Consumers' trust and uncertainty avoidance}

It is much harder for consumers, via e-commerce, to see whether the quality of the product is good or not. Therefore, many consumers are oftentimes careful, as they are uncertain when buying a product online (Pappas, 2016). Consumers with more trust are more willing to engage online (Azar et al., 2016). Gaining the trust of consumers is a crucial part of e-commerce and very important for sellers to consider within their marketing strategies (Chen \& Barnes, 2007). According to Hajili (2014), trust in social networking sites is even a key predictor of purchase, mainly because social media platforms help sellers connect more directly with their consumers, leading to increased trust and intention to buy. Remarkably, investigations that go into factors that induce trust on Instagram are scarce (Din et al., 2018). When consumers perceive a lack of trust within online retail environments, they are not willing to purchase (Broeder, 2020), Thus, trust and purchase intention are positively linked with each other, indicating that when consumers trust the seller, they are more willing to buy their products (Che et al., 2017).

Based on previous studies on consumer behavior, Broeder (2020) identified three types of trust: (a) initial trust, (b) trustworthiness, and (c) trust propensity. Initial trust refers to the consumers' initial perceptions of the shopping environment, describing their intentions to accept vulnerability based on the positive expectations of subsequent actions. In fact, it is a contextdependent subjective personal characteristic of a specific shopping environment gauged by a specific consumer. Trustworthiness, on the other hand, refers to the ability, willingness, and integrity of a shopping environment proving to be the basis for consumers' familiarity with online purchase transactions. Finally, trust propensity refers to the distinct dispositional attribute of a person and their general tendency to trust others; the willingness to depend on situations, persons, or both and the independence of the online shopping environment. 
Culture-related differences in uncertainty avoidance have an essential influence on consumers' online trust (Sahi et al., 2016; Zhou et al., 2007) and online behavior (Yıldırım et al., 2016; Yu et al., 2018). The degree of uncertainty avoidance is one of the dimensions in Hofstede's (2021) most commonly used cross-cultural paradigm (see also Minkov, 2018). Cultural differences in uncertainty avoidance refer to "the extent to which the members of institutions and organizations within a society feel threatened by uncertain, unknown, ambiguous, or unstructured situations" (Hofstede, 2021). The difference is made between low and high uncertainty avoidance countries. High uncertainty countries are more conservative and structured. Low uncertainty avoidance countries are more open-minded towards change or innovation. In high uncertainty avoidance (national) cultures, feelings of trust dominate decision-making, whereas in low uncertainty avoidance cultures, more information sources are used for decision-making (Park et al. 2012; Goodrich \& de Mooij, 2013).

\section{Research context: Product tagging on Instagram}

As a social media platform, Instagram consists of user profiles communicating through pictures, photos, or video clips that are accompanied by short verbal descriptions. Tagging is an important social activity where users can tag people in pictures or within the text beneath the picture. Using tags enable users to obtain a broader reach and, hence, acquire more followers. Another one of its features is hash tagging, which is the use of the 'hash' symbol (\#) in front of a word (e.g., \#nice or \#beautiful), expressing or describing the content of the picture. Clicking on the hashtag reveals a collection of pictures from other users who have used the same hashtag. When uploading a picture, users can type in Instagram usernames and select the person they want to tag. The interpersonal communication motives of users lead to tagging people, as it helps them conveniently connect and engage with their friends. Besides hash tagging and tagging people, Instagram launched a new feature in 2018, equipping users with the ability to tag products. The feature is illustrated in Figure 1 for a socalled "oversized blouse" offered by the international fashion retailer ZARA.
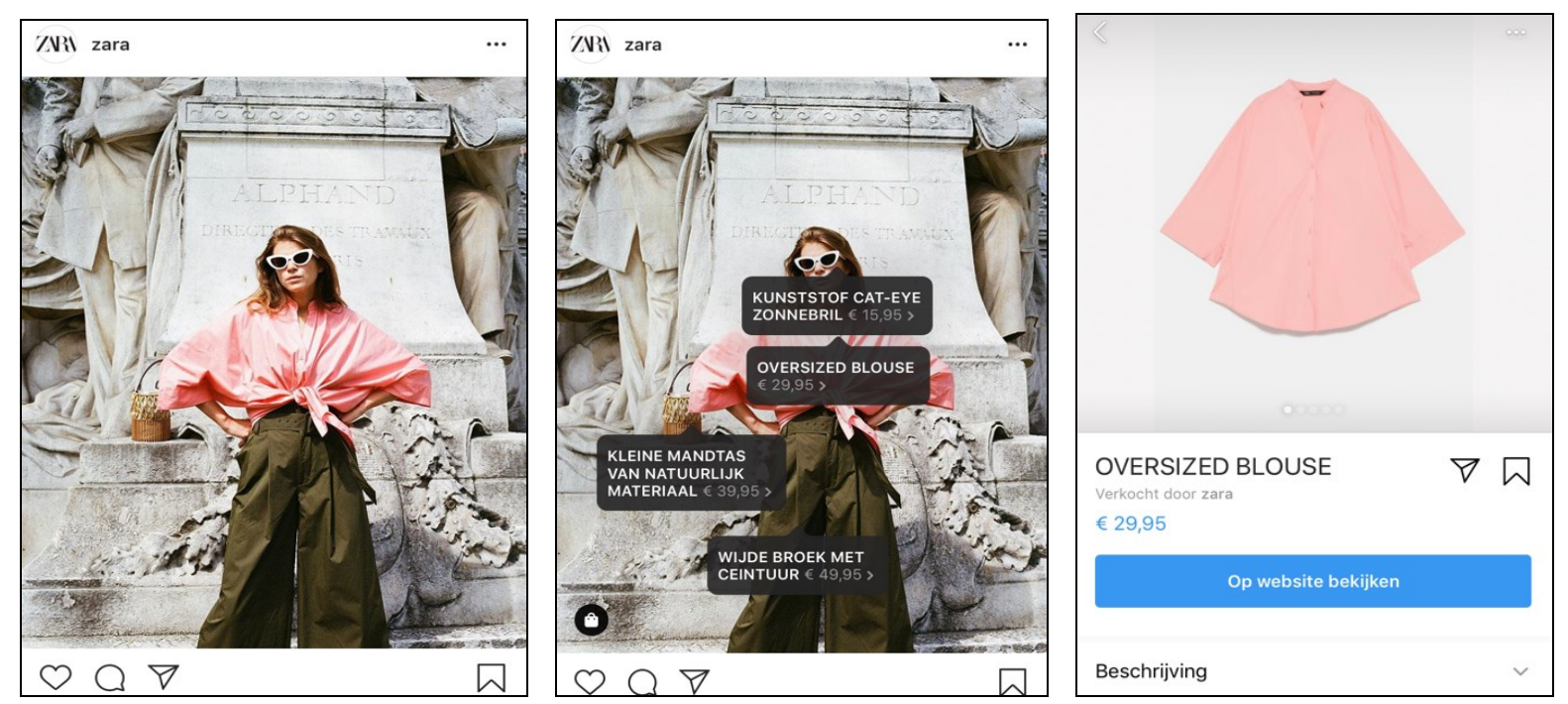

Figure 1. ZARA's "oversized blouse" on Instagram: without tagging (left), with product tags (middle), and in the shop section (right).

The navigation menu displays a shopping bag icon (-); if tapped, detailed information about the product is provided, such as the name or price. Then, the user is directed to the Instagram shop section of the seller without having to exit the app. This path of shopping has succeeded in enhancing users' shopping experiences. 


\section{METHODOLOGY}

\section{Research question and hypotheses}

The research question of this study is formulated as follows: what is the effect of the presence of an Instagram product tag on consumers' trust and purchase intentions, and how does this affect present itself across different cultures?

In an online environment, the availability of product information is very distinctive since online shopping only provides consumers with a narrow vision of the product. Clearly, two pieces of information are better than one. Accordingly, the verbal product appeals are as important as the visuals. For this reason, it could be expected that adding product text tags will lead to higher trust and purchase intentions, as they complement the visuals. The following hypotheses are proposed:

Hypothesis 1: An Instagram product tag induces purchase intentions among consumers.

Hypothesis 2: An Instagram product tag induces trust among consumers.

In this study, members from two distinct cultures participated: Dutch and Paraguayan. According to the cross-cultural paradigms of Hall (1976) and Hofstede (2021), the Netherlands has a low-context (text and explicit preferred) culture with a "slight preference" for avoiding uncertainty (UA score of 53 on a $0-100$ scale). In contrast, Paraguay has a high-context (visual and implicit preferred) culture and scores "very high" on uncertainty avoidance (UA score of 85).

Thus, cues such as Instagram product text tags might increase consumers' purchase intentions within higher context cultures (i.e., Paraguay), as they help to further reduce consumers' uncertainties when shopping. In contrast, lower uncertainty cultures (i.e., the Netherlands) do encounter less uncertainty within the online retail environment and would require fewer textual cues like product tags to purchase products online. Hence, the following hypothesis:

Hypothesis 3: The effect of Instagram product tagging on trust and purchase intentions is influenced by the cultural background of consumers.

This study had a two (product tag: absent vs. present) by two (culture: Dutch vs. Paraguayan) between-subjects experimental design. The dependent variables were purchase intention and trust. In the conceptual model, culture was assumed to moderate the relationships between product tagging, purchase intention, and trust. The conceptual model, with the position of the three hypotheses, is shown in Figure 2.

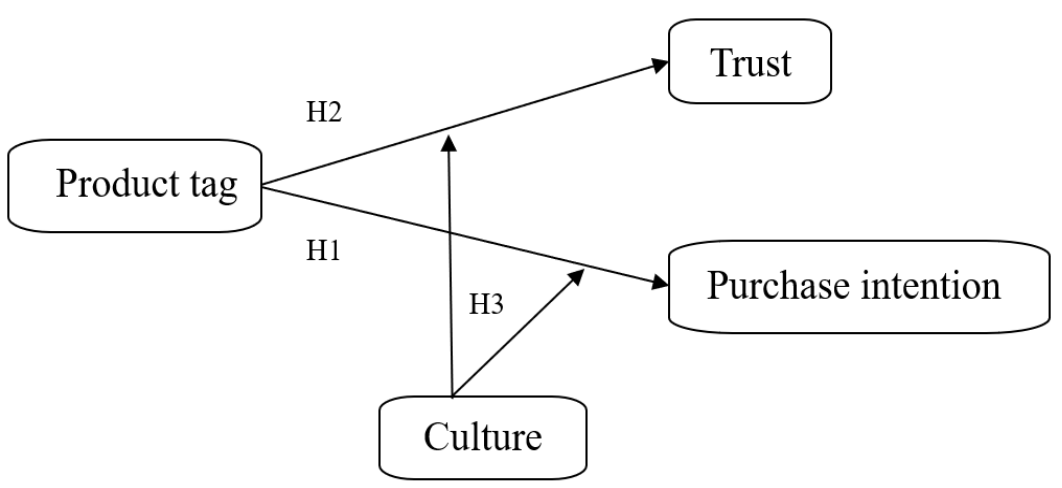

Figure 2. Conceptual model of the present study. 


\section{Sample}

In total, 281 persons completed the online survey. The final sample used in the analyses consisted of 225 female participants. Data were not analyzed from 14 persons living/born outside Paraguay or the Netherlands and from 42 persons failing the manipulation check (below). Altogether, 143 participants were from the Netherlands (mostly from Tilburg and Utrecht) and 82 from Paraguay (mostly from Asunción). Their Dutch or Paraguayan background were checked by asking the question "To what ethnic group do you belong?" The mean age was 25 (age range: 16-56), and the education level of most participants was higher education or university.

\section{Stimulus material}

The participants saw a picture of a blue blouse-an image from ZARA —on an Instagram page. This fashion retailer is active both in Paraguay and the Netherlands. The blouse and the blurred background (including the ZARA logo) were considered neutral to reduce any distractions. There were two variations of the Instagram page (see Figure 3). In the no-tag page, there was no product tag. In the other, the following product tag was given: "SNOWDOT BLOUSE \$ $25.00>$ >.

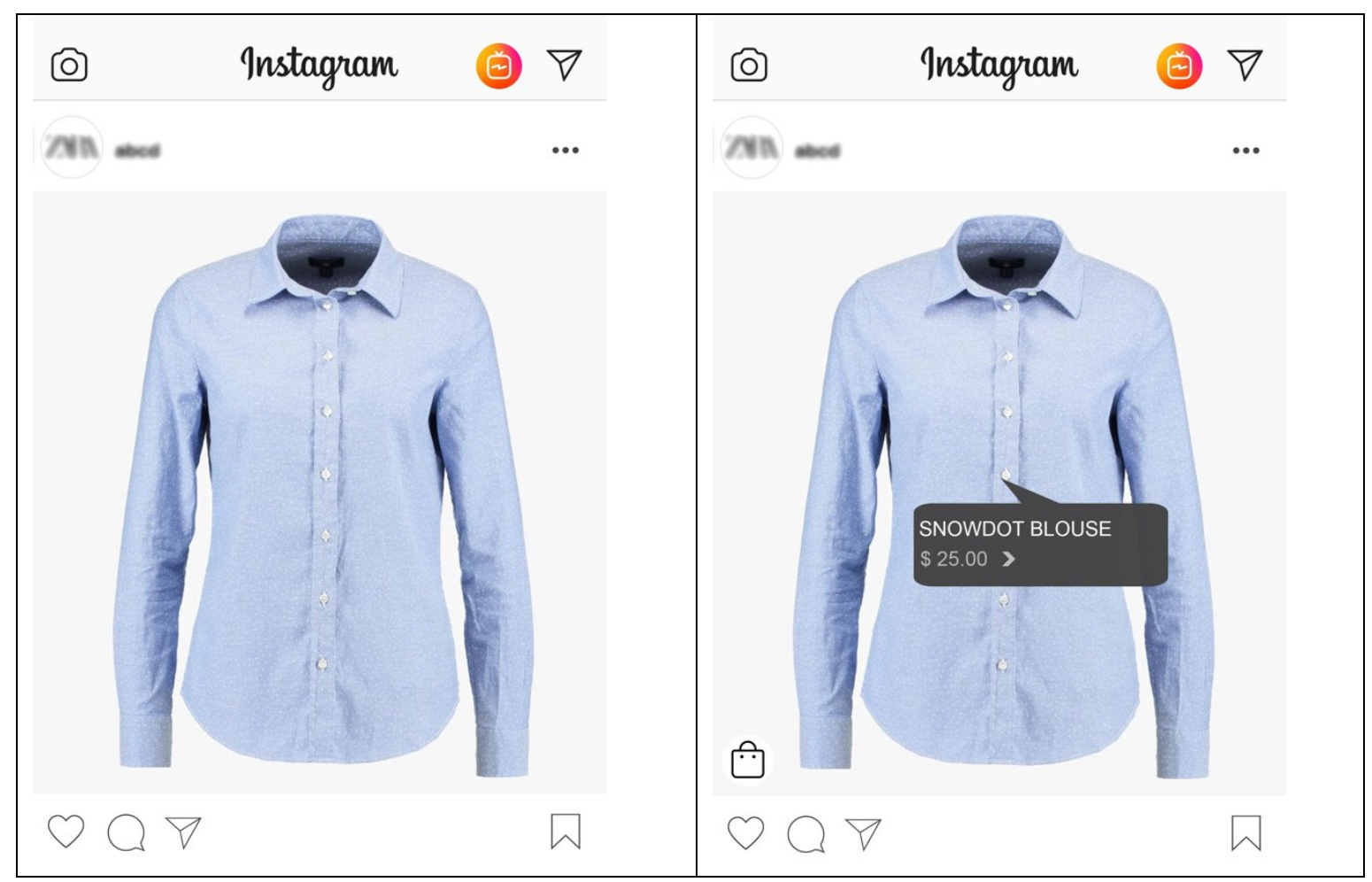

Figure 3. Blouse offered in an Instagram post without a product tag (left) and with a product tag (right).

In a pilot study, eight Dutch women (experts in online marketing) were consulted in qualitative interviews. They agreed that the Instagram page was realistic (for a feminine blue blouse) and that the intended manipulation was adequately expressed through the absence/presence of the product tag. Some minor suggestions were made by the participants in the pilot, such as the price of the blouse should be in dollars, the ZARA logo should be more blurred, and some respondents in the main study might see the product tag as a price tag. Suggestions of the pilot participants were taken care of in the final stimuli and questionnaire. 


\section{Procedure and measures}

Data were collected though snowball sampling via social media (WhatsApp and Facebook) of acquaintances in Paraguay (mostly studying at the Universidad Americana or the Universidad Nacional de Asunción) and the Netherlands (mostly studying at the universities of Tilburg and Utrecht). The respondents participated in the study through an online link. They gave their informed consent and answered an online Qualtrics questionnaire (in English) that included the demographic variables age, gender, birth country, and country of living. Based on their ethnic self-identification, participants were randomly assigned to one of the two conditions in which the two Instagram images of the blue blouse were shown (see Figure 3). In the no-tag condition, the blouse was offered in an Instagram post without a product tag, that is, with only a visual appeal. In the tag-condition, a product tag was added to the blouse; thus, the product presentation of the blouse in this condition had a visual and a textual appeal.

The participants were asked to imagine a simple scenario: "you are looking for a simple blouse" and were asked a few questions based on it. The items of the questionnaire are available in the Appendix and the answers were given on a five-point Likert-type scale (from $1=$ "Completely disagree" to $5=$ "Completely agree").

- Purchase intention was measured with one statement ("I would like to buy this product").

- Consumer trust was measured with statements on initial trust (e.g., "This website is trustworthy"), trustworthiness (e.g., "Prior online purchase experiences from other websites make me feel comfortable in using this website"), and trust propensity (e.g., "It is easy for me to trust a person"). The trust scale was validated in several cross-cultural investigations (see Broeder, 2020) and had good internal consistency in this study, with Cronbach's $\alpha=0.84$.

- Uncertainty avoidance was measured with items adapted from Jung and Kellaris (2004) (e.g., "I prefer structured situations to unstructured situations"). This scale had acceptable reliability in this study with Cronbach's $\alpha=0.78$.

- Questions were asked regarding the participants' familiarity with the online purchasing of products via Instagram.

- Product attitude ("How do you feel about the product?") was measured with contrasting adjective pairs: product knowledge (e.g., "bad/good quality"), hedonic (e.g., "ugly/good-looking"), utilitarian (e.g., "pointless/useful"). This was a newly constructed scale. The internal consistency was good with Cronbach's $\alpha=0.85$.

- Finally, for the conditional manipulation, the participants had to indicate with a "yes" or "no" on whether they saw an Instagram post with or without a price tag.

\section{Manipulation check}

Some analyses were done to check the correctness of the assumed manipulation. First, in the no-tag condition, 114 of the 141 participants (81\%) correctly reported that they saw an Instagram without a price tag. In addition, in the with-tag condition, 111 of the 126 participants (88\%) correctly reported that they saw an Instagram post with a price tag. The answers of the participants who did not correctly remember the absence/presence of the product tag of the condition in which they participated $(N=42)$ were not analyzed further. The final sample for testing the hypotheses included 225 participants. The second manipulation check concerned the attitude towards the blouse presented in the Instagram post. An analysis of variance revealed no statistically significant differences (and interactions) in the product attitude between the conditions $[F(1,221)=0.286, p=0.593]$ and the cultural groups $[F(1,221)=1.334, p=0.249]$. Therefore, on average, there were no differences between the Dutch and Paraguayan subsample in what they knew and how they felt (hedonic and utilitarian) about the product in the experiment. The performed manipulation checks warranted the successful manipulation of (random) assignment of the Dutch and Paraguayan participants to the two conditions. 


\section{RESULTS}

\section{Preliminary Analyses}

The assumed cultural difference between the subsamples, based on Hofstede (2021), indeed surfaced in the degree of uncertainty avoidance. That is, on average, the Paraguayans (with $M_{\text {Par }}=3.68$ and $S D_{\text {Par }}=0.58$ ) reported higher uncertainty avoidance than the Dutch (with $M_{\text {Dut }}=3.16$ and $S D_{\text {Dut }}=$ 0.58). This difference, $M_{\text {Diff }}=0.52$, was significant, $t(223)=-6.48, p<0.001$, and represented a large effect size of Cohen's $d=0.89$. On average, the Dutch respondents were more familiar with purchasing products online (with $M_{\text {Dut }}=4.25$ and $S D_{\text {Dut }}=0.71$ ) than the Paraguayan respondents (with $M_{P a r}=3.67$ and $\left.S D_{\text {Par }}=0.99\right)$, where $t(128.565)=4.66$ and $p<0.001$ with a medium effect of $d=0.89$. Additionally, familiarity with Instagram purchasing of the Dutch was lower (with $M_{\text {Dut }}=2.30$ and $S D_{\text {Dut }}$ $=1.25$ ) than the Paraguayans (with $M_{\text {Par }}=2.89$ and $S D_{\text {Par }}=1.14$ ), where $t(223)=-3.52$ and $p<0.001$ with a medium effect of $d=0.89$.

\section{Hypotheses testing}

It was hypothesized that with product tagging, consumers would have higher purchase intentions (Hypothesis 1), differentiated by cultural background (Hypothesis 3). The average levels of purchase intention for the no-tag condition and with-tag condition for both groups are plotted in Figure 4.

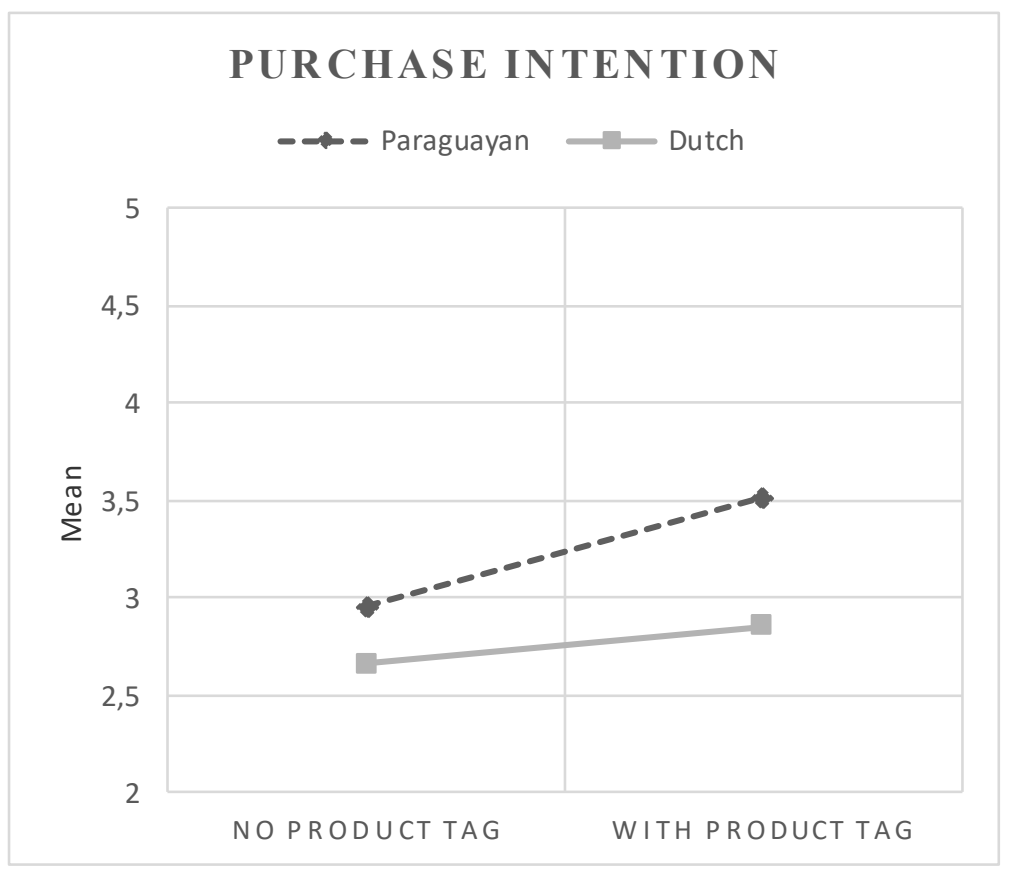

Figure 4. Purchase intention per condition and cultural group (Mean scores on a 5-point Likert-type scale, "Completely (dis)agree", Min. = 1 and Max. = 5).

In both conditions, the mean purchase intention of the Paraguayan group (from $M_{\text {No-tag }}=2.95$ with $S D_{\text {No-tag }}=1.10$ to $M_{\text {With-tag }}=3.51$ with $S D_{\text {With-tag }}=0.94$ ) was higher compared to the Dutch group (from $M_{N o \text {-tag }}=2.66$ with $S D_{\text {No-tag }}=1.11$ to $M_{\text {With-tag }}=2.85$ with $S D_{\text {With-tag }}=1.17$ ). A two-by-two betweengroups analysis of variance was conducted to explore the impact of product tagging and cultural background on the levels of purchase intention. The interaction effect was not statistically significant. The main effect for condition reached statistical significance, $F(1,221)=6.087, p=0.014$; however, the effect size was small, $\eta_{p}{ }^{2}=0.027$. These findings revealed that the presence of a product tag had a positive effect on purchase intentions as compared to a product offer without a verbal tag (confirming Hypothesis 1), for both the Dutch as well as Paraguayan groups. Moreover, there was a notable 
statistical main effect for culture $F(1,221)=9.655, p=0.002$, with a medium effect size, $\eta_{p}{ }^{2}=0.042$, which supported Hypothesis 3 . This means that the direct product tagging effect on the mean purchase intention of the Paraguayan group was higher than the Dutch group.

It was also hypothesized that product tagging would provide more consumer trust (Hypothesis 2), differentiated by cultural background (Hypothesis 3). The average levels of trust for the no-tag condition and with-tag condition for both groups are plotted in Figure 5.

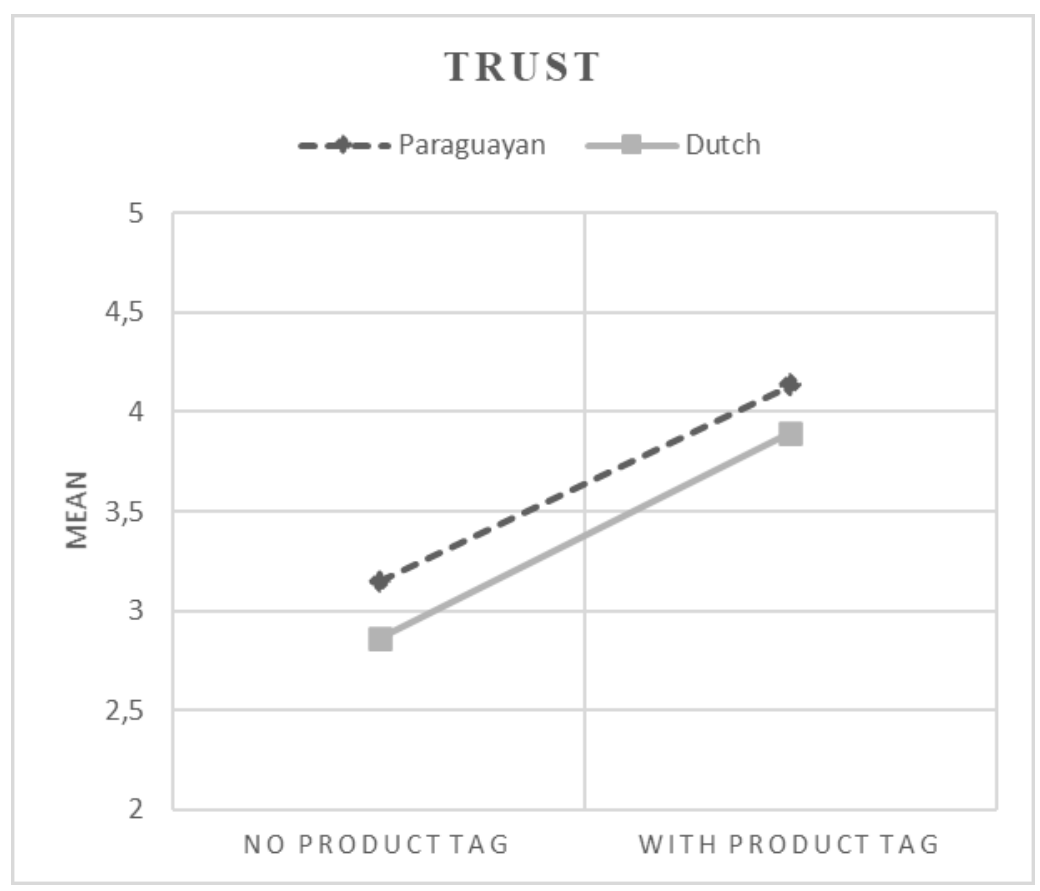

Figure 5. Initial trust per condition and cultural group (Mean scores on a 5-point Likert-type scale, "Completely (dis)agree", Min. = 1 and Max. = 5).

Figure 5 presents that initial trust in the website increased when the blouse had a product tag. Both the Paraguayan group (from $M_{\text {No-tag }}=3.15$ with $S D_{\text {No-tag }}=0.67$ to $M_{\text {With-tag }}=4.13$ with $S D_{\text {With-tag }}=$ 0.75 ) and the Dutch group (from $M_{\text {No-tag }}=2.86$ with $S D_{\text {No-tag }}=0.66$ to $M_{\text {With-tag }}=3.90$ with $S D_{\text {With-tag }}=$ 0.93 ) had higher levels of trust in the with-tag condition compared to the no-tag condition. A two-way between-groups analysis of covariance was conducted to assess the effect of product tagging in increasing initial trust for both groups. In the analysis, trustworthiness and trust propensity were entered as covariates to control for individual differences. The interaction effect was not statistically significant. For trust, the main effect for the condition was statistically significant $F(1,219)=48.377, p$ $<0.001$; the effect size was large, $\eta_{p}{ }^{2}=0.18$. This meant that adding a product tag also created more trust (confirming Hypothesis 2). Further, the main effect for culture did not reach statistical significance $F(1,219)=4.249, p=.040, \eta_{p}{ }^{2}=0.019$. Thus, no significant difference in the mean level of perceived trust was noted, between the Dutch and Paraguayan samples, in both conditions (Hypothesis 3).

\section{DISCUSSION AND IMPLICATIONS}

Selling products on social media platforms will be a new shopping mode for most consumers. On Instagram, sellers already could use visual stimuli, and with the emergence of product tags, visual and verbal information can now be combined in an Instagram post. Subsequently, with the "shop now" function, the consumers can directly go to the online store, which substantially shortens the shopping path. The present study focused on this in-app shopping. For a virtual mock-up shop on Instagram, the findings demonstrated that text tags effectively complement the visual product presentation. The text 
tags affected the content of the message (higher trust) and had a persuasive impact on consumer intentions (higher purchase). The information value of visual and textual cues of online product presentations in the atmospheric trust of in-app shopping was supported for both cultural groups, the Dutch as well as the Paraguayan.

The findings of this study give some appealing suggestions for online product presentation that have interesting theoretical and managerial implications: specifically, which modality represents what information and how is this information processed.

First, the findings suggest that specific visual and textual features might play a different role in the decision-making process of the consumer (Richard \& Chebat, 2016). Images are usually more emotionally evocative than words (Blackwell, 2020; Van Esch et al., 2019; Holmes \& Mathews, 2005). Therefore, initially, the image of a product presentation attracts the attention of the searching consumer (e.g., "That blouse has a nice color"). The visuals are persuasive in conversing the consumer to the next step, considering the product more in detail. Subsequently, the text tags of the product presentation initiate more global and abstract thinking (Amit et al., 2013) (e.g., "This blouse is oversized and expensive"). Ultimately, the role of textual attributes in the product information is to persuade the consumer to purchase the product.

Second, the effect of the textual appeal in the visual product presentation evidence in this investigation depends on differences in the information processing style of individuals (Sojka \& Giese, 2001). Consumers prevailing an emotional processing style ("Preference for affect") are triggered more by visual information, whereas others with a more discursive processing style ("Need for cognition") are affected more by verbal information (Haugtvedt et al., 1992; Richard \& Chebat, 2016). Admittedly, the distinction of two processing styles is rather simple, but nonetheless validated through a diversity of investigations. For example, Martin et al.'s (2005) study on processing of website information revealed that individuals in higher need for cognition evaluated websites with high verbal and low visual complexity more favorably. In a similar vein, Kim (2019), in an apparel ecommerce context, noted the moderating role of need for cognition for the effects the concreteness of verbal/visual stimuli in both imaginary and discursive processing. Further, Visentin and Tuan (2021) found the superiority of visual cues on the bellyband (the paper wrapping of books). However, differences in the need for affect and the effect on purchasing behavior were not supported.

Third, in this study, the assumed cultural difference between the subsamples, based on Hofstede (2021), indeed surfaced in the degree of uncertainty avoidance: the Paraguayans reported higher uncertainty avoidance than the Dutch. In addition, on average the Dutch respondents were more familiar with purchasing products online, whereas the Paraguayans respondents were more familiar with purchasing products on Instagram. However, there were no cultural moderations (that is, more or less strengthening) of the relationships between the absence (vs. presence) of product tags, perceived trust, and purchase intention. Vander Schee et al. (2020) conclude in their meta review that there is a lack of comprehensive marketing studies that integrate factors of online consumer engagement. One of these factors is the cultural dimension of individualism/collectivism. Further investigation might explore other cultural facets apart from uncertainty avoidance. One could assume that members of a high collectivistic society (such as Paraguay) with "commitment to a strong, cohesive in-group" tend to be less impulsive to purchase when a product is present in an Instagram post compared to a high individualistic society (such as the Netherlands), in which members are "supposed to look after themselves and their direct family only" (Hofstede, 2021).

Finally, this study hopes to give rise to the importance of considering local cultural-related consumer preference in the global ambiance of e-commerce, with ethnically self-identified cultural consumer groups. In almost all prior cross-cultural studies, cultural identification of groups is based on nationality, the country of residence or that of birth. The original theoretical claim of this study is that self-categorization is a better way to identify cultural groups compared to categorization based on nationality and country. In this study, the Dutch and Paraguayan groups were distinguished by the cultural profiles based on country of birth, country of living, and self-identification criteria. This multiple identification has proven to be a highly valid one for defining cultural groups in Asia, Europe and South Africa (Broeder \& Stokmans, 2013). 
In a variety of cross-cultural studies, comparisons are attached to Hall's (1976) notion of contexting. Remarkably, there is hardly any empirical support for the commonly accepted distinction made between high-context and low-context cultures. Broeder (2021) applied the multiple cultural identification in exploring informed communication styles in high-low-context cultures (Dutch, Greek, and Japanese). Clear differences were found between the cultural groups in their reported communication style. The Dutch used relatively more non-verbal communication, the Greeks used more hand gestures, and the Japanese were more indirect in their communication. Interestingly, a cultural divergence emerged: the Greeks living in the Netherlands reported higher levels of non-verbal communication, were more indirect, and used more metaphors than did the Greeks living in Greece. Unfortunately, in Hall's (1976) context theory, South American cultures are lacking. Therefore, the premise should be made that these cultures are high-context cultures and more visual and less verbal oriented, compared to low-context cultures in Western Europe.

\section{Limitations and further investigations}

Of course, some limitations provide valuable input for future work. First, one of the limitations of this study lay in the fact the questionnaire was drafted in English, which is not the native language for both the Dutch and Paraguayan participants. Future studies might provide a precise, reliable translation in the native language, to ensure the most accurate responses from them. This is an important point of attention in cross-cultural investigations (Harzing, 2005).

Second, this study chose only one product (i.e., a female blouse). Future studies can include different products to control for confounding variables like consumers' clothing taste. Further research can seek to determine the effectiveness of the presence of a verbal product tag within different industries. For instance, comparing the clothing branch with the furniture branch or electronics.

Third, the relationship between image and text is more complex than the mere presence effect (Li \& Xie, 2020). The prominence salience of an appeal in a product presentation might also depend on the relative importance of competing cues. Specifically, color variations of the product context have been shown to provoke trust (i.e., blue) (Broeder \& Van Doremalen, 2021; Broeder \& Snijder, 2019) or emotion (i.e., red) (Broeder \& Wildeman, 2021), within the online shopping environment. Future visual marketing studies might explore more in detail the complexity of information contained in the image itself (Overgoor et al., 2020; Song et al., 2018) as well as in the context of the image (Maier \& Dost, 2018; Yoo \& Kim, 2014).

A fourth limitation relates to the realism of the experimental design and measuring behavioral intention in consumer research (see discussions by Morales at al., 2017 and Wutich et al., 2021). The current study strived to increase external validity by displaying an Instagram post that looked as real as possible within the survey. However, the brand name of the post was blurred, so the participants were not aware of who the seller was. Online consumers will likely be more eager to buy from familiar brands than unfamiliar ones; therefore, including branding could be interesting for future studies. Moreover, future work can examine if the product tag is more beneficial for unfamiliar brands than familiar brands, as it has been established that product tags increase consumers' feelings of trust. In this respect, Phua et al. (2017) noted that Instagram users have high brand community engagement and commitment, compared to users of three other social network platforms, that is, Facebook, Twitter or Snapchat.

Finally, only female consumers participated in this study. In further research, products that cater to both men and women can be used in the comparison. In addition, Djafarova and Bowes (2021) found gender differences in relation to impulse purchasing behavior on Instagram: women were more encouraged than men. Recent content analyses identified gender-specific image tagging behavior (related to emotions and feelings) by Instagram users (Philipps \& Dorsch, 2019; Song et al., 2018). 


\section{CONCLUSION}

This study confirmed the positive shopping atmospherics of Instagram in-app shopping. Moreover, it was found that the presence of a product tag had a positive effect on purchase intentions and perceived trust, compared to a product offer without a verbal tag. This was found for both the European as well as the South American female consumers. Although members of the Dutch and Paraguayan cultural groups reported different levels of uncertainty avoidance, no different levels of trust in the different product presentation were perceived. With a globalized online world, culture as a set of individual shared common thoughts and attitudes will disperse and reinforce. Further studies could investigate the fine-tuning of persuasive product information cues in advertisements and marketing communications to local consumer preferences in global operating social commerce platforms.

\section{Acknowledgment}

The authors would like to thank the anonymous reviewers for their insightful suggestions and critical reading of the manuscript. This improved the quality of the final paper.

\section{References}

Amit, E., Wakslak, C., \& Trope, Y. (2013). The use of visual and verbal means of communication across psychological distance. Personality and Social Psychology Bulletin, 39(1), 43-56. https://doi.org/10.1177/0146167212460282

Azar, S.L., César Machado, J., Vacas-De-Carvalho, L., \& Mendes, A. (2016). Motivations to interact with brands on Facebook - towards a typology of consumer-brand interactions, Journal of Brand Management, 23(2), 153-178. https://doi.org/10.1057/bm.2016.3

Babić Rosario, A., Sotgiu, F., De Valck, K., \& Bijmolt, T. H. (2016). The effect of electronic word of mouth on sales: A meta-analytic review of platform, product, and metric factors. Journal of Marketing Research,53(3), 297-318. https://doi.org/10.1509/imr.14.0380

Blackwell, S. E. (2020). Emotional mental imagery. In Abraham, A. (ed) (2020). The Cambridge handbook of the imagination, Cambridge University Press.

Blanco, C. F., Sarasa, R. G., \& Sanclemente, C. 0. (2010). Effects of visual and textual information in online product presentations: Looking for the best combination in website design. European Journal of Information Systems, 19(6), 668-686. https://doi.org/10.1057/ejis.2010.42

Broeder, P. (2020). Culture, privacy, and trust in E-commerce. Marketing from Information to Decision Journal, 3(1), 14-26. https://doi.org/10.2478/midj-2020-0002

Broeder, P. (2021). Informed communication in High Context and Low Context cultures.Journal of Education, Innovation, and Communication,3(1), 13-24. https://doi.org/10.34097/jeicom-3-1-june21-1

Broeder, P., \& Snijder, H. (2019). Color in online advertising: Going for trust, which blue is a must? Marketing - from Information to Decision Journal, 2(1), 5-15 https://doi.org/10.2478/midj-2019-0001

Broeder, P., \& Stokmans, M. (2013). Why should I read? A cross-cultural investigation into adolescents' reading socialization and reading attitude. International Review of Education, 59(1), 87-112. https://doi.org/10.1007/s11159-013-9354-4 
Broeder, P., \& Van Doremalen, L. (2021). Persuasive colors for trust in E-commerce: Dutch blue or Russian red? Russian Journal of Communication, 1-14. https://doi.org/10.1080/19409419.2021.1951066

Broeder, P., \& Wildeman, N. (2020). The color red for emotion in cross-cultural E-commerce. Eurasian Journal of Business and Economics, 13(25), 75-89. https://doi.org/10.17015/ejbe.2020.025.05

Che, J. W., Cheung, C. M., \& Thadani, D. R. (2017). Consumer purchase decision in Instagram stores: The role of consumer trust. In Proceedings of the 50th Hawaii International Conference on System Sciences (pp. 24-33). https://doi.org/10.24251/HICSS.2017.004

Chen, Y., \& Barnes, S. (2007). Initial trust and online buyer behavior. Industrial Management \& Data Systems, 107(1), 21-36. https://doi.org/10.1108/02635570710719034

De Mooij, M. (2019). Consumer behavior and culture: Consequences for global marketing and advertising. London: Sage.

De Oliveira Santini, F., Ladeira, W. J., Pinto, D. C., Herter, M. M., Sampaio, C. H., \& Babin, B. J. (2020). Customer engagement in social media: a framework and meta-analysis. Journal of the Academy of Marketing Science, 48, 1211-1228. https://doi.org/10.1007/s11747$\underline{020-00731-5}$

Din, S. M., Ramli, R., \& Bakar, A. A. (2018). A review on trust factors affecting purchase Intention on Instagram. In 2018 IEEE Conference on Application, Information and Network Security (AINS) (pp. 49-53).

Djafarova, E., \& Bowes, T. (2021). 'Instagram made me buy it': Generation Z impulse purchases in fashion industry. Journal of Retailing and Consumer Services, 59, 102345. https://doi.org/10.1016/i.jretconser.2020.102345

Giannoulakis, S., \& Tsapatsoulis, N. (2016). Evaluating the descriptive power of Instagram hashtags. Journal of Innovation in Digital Ecosystems, 3(1), 114-129. http://dx.doi.org/10.1016/j.jides.2016.10.001

Goodrich, K., \& de Mooij, M. (2013). How 'social' are social media? A cross-cultural comparison of online and offline purchase decision influences. Journal of Marketing Communications, 20(1/2), 103-116. https://doi.org/10.1080/13527266.2013.797773

Ha, Y., Park, K., Kim, S. J., Joo, J., \& Cha, M. (2020). Automatically detecting image-text mismatch on Instagram with Deep Learning. Journal of Advertising, 50(1), 52-62. https://doi.org/10.1080/00913367.2020.184309

Hajili, M. N. (2014). A study of the impact of social media on consumers. International Journal of Market Research, 56(3), 387-404. https://doi.org/10.2501/IJMR-2014-025

Hall, E. T. (1976). Beyond culture. New York: Doubleday.

Hall, E. T. \& Hall, M. R. (1990). Understanding cultural differences: German, French, and Americans, Yarmouth, ME: Intercultural Press.

Haugtvedt, C. P., Petty, R. E., \& Cacioppo, J. T. (1992). Need for cognition and advertising: Understanding the role of personality variables in consumer behavior. Journal of Consumer Psychology, 1(3), 239-260. https://doi.org/10.1016/S10577408(08)80038-1

Harzing, A. (2005). Does the use of English-language questionnaires in cross-national research obscure national differences? International Journal of Cross-Cultural Management, 5(2), 213-224. https://doi.org/10.1177/1470595805054494

Hofstede, G. (2001). Culture's consequences: Comparing values, behaviors, institutions and organizations across nations. London: Sage publications.

Hofstede, G. (2021). Country Comparison. Retrieved from www.hofstede-insights.com 
Hollebeek, L. D. (2018). Individual-level cultural consumer engagement styles. International Marketing Review, 35(1), 42-71. https://doi.org/10.1108/IMR-07-2016-0140

Holmes, E. A., \& Mathews, A. (2005). Mental imagery and emotion: A special relationship? Emotion, 5(4), 489-497. https://doi.org/10.1037/1528-3542.5.4.489

Jung, J. M., \& Kellaris, J. J. (2004). Cross-national differences in proneness to scarcity effects: The moderating roles of familiarity, uncertainty avoidance, and need for cognitive closure. Psychology \& Marketing, 21(9), 739-753. https://doi.org/10.1002/mar.20027

Kim, M. (2019). Digital product presentation, information processing, need for cognition and behavioral intent in digital commerce. Journal of Retailing and Consumer Services, 50, 362-370. https://doi.org/10.1016/j.jretconser.2018.07.011

Kim, M., \& Lennon S. J. (2008). The effects of visual and verbal information on attitudes and purchase intentions in internet shopping. Psychology and Marketing, 25(2), 146-178. https://doi.org/10.1002/mar.20204

Klostermann, J., Plumeyer, A., Böger, D., \& Decker, R. (2018). Extracting brand information from social networks: Integrating image, text, and social tagging data. International Journal of Research in Marketing, 35(4), 538-556. https://doi.org/10.1016/j.ijresmar.2018.08.002

Lee, D., Hosanagar, K., \& Nair, H. S. (2018). Advertising content and consumer engagement on social media: Evidence from Facebook. Management Science, 64(11), 5105-5131. https://doi.org/10.1287/mnsc.2017.2902

Li, Y., \& Xie, Y. (2020). Is a picture worth a thousand words? An empirical study of image content and social media engagement. Journal of Marketing Research, 57(1), 1-19. https://doi.org/10.1177/0022243719881113

Maier, E., \& Dost, F. (2018). The positive effect of contextual image backgrounds on fluency and liking. Journal of Retailing and Consumer Services, 40, 109-116. https://doi.org/10.1016/j.jretconser.2017.09.003

Martin, B. A., Sherrard, M. J., \& Wentzel, D. (2005). The role of sensation seeking and need for cognition on web-site evaluations: A resource-matching perspective. Psychology \& Marketing, 22(2), 109-126. https://doi.org/10.1002/mar.20050

Minkov, M. (2018). A revision of Hofstede's model of national culture: Old evidence and new data from 56 countries. Cross Cultural and Strategic Management, 25(2), 231-256. https://doi.org/10.1108/CCSM-03-2017-0033

Morales, A. C., Amir, O., \& Lee, L. (2017). Keeping it real in experimental researchUnderstanding when, where, and how to enhance realism and measure consumer behavior. Journal of Consumer Research, 44(2), 465-476. https://doi.org/10.1093/icr/ucx048

Mosunmola, A., Adegbuyi, O., Kehinde, O., Agboola, M., \& Olokundun, M. (2019). Perceived value dimensions online shopping intention: The role of trust and culture. Academy of Strategic Management Journal, 18(1), 1-20.

Overgoor, G., Rand, W., \& Van Dolen, W. (2020). The champion of images: Understanding the role of images in the decision-making process of online hotel bookings. In Proceedings of the 53rd Hawaii International Conference on System Sciences (pp. 4069-4078). https://doi.org/10.24251/HICSS.2020.498

Pappas, N. (2016). Marketing strategies, perceived risks, and consumer trust in online buying behavior. Journal of Retailing and Consumer Services, 29, 92-103. https://doi.org/10.1016/j.jretconser. 2015.11.007

Park, J., Gunn, F., \& Han, S. L. (2012). Multidimensional trust building in e-retailing: Crosscultural differences in trust formation and implications for perceived risk. Journal of 
Retailing and Consumer Services, 19(3), 304-312. https://doi.org/10.1016/i.jretconser.2012.03.003

Phua, J., Jin, S. V., \& Kim, J. J. (2017). Gratifications of using Facebook, Twitter, Instagram, or Snapchat to follow brands: The moderating effect of social comparison, trust, tie strength, and network homophily on brand identification, brand engagement, brand commitment, and membership intention. Telematics and Informatics, 34(1), 412-424. http://dx.doi.org/10.1016/j.tele.2016.06.004

Philipps, J., \& Dorsch, I. (2019). Gender-specific tagging of images on Instagram. In International Conference on Human-Computer Interaction (pp. 396-413). Springer, Cham.

Richard, M. O., \& Chebat, J. C. (2016). Modeling online consumer behavior: Preeminence of emotions and moderating influences of need for cognition and optimal stimulation level. Journal of Business Research, 69(2), 541-553. https://doi.org/10.1016/j.jbusres.2015.05.010

Rietveld, R., Van Dolen, W., Mazloom, M., \& Worring, M. (2020). What you feel, is what you like influence of message appeals on customer engagement on Instagram. Journal of Interactive Marketing, 49(2), 20-53. https://doi.org/10.1016/i.intmar.2019.06.003

Sahi, G. K., Sekhon, H. S., \& Quareshi, T. K. (2016). Role of trusting beliefs in predicting purchase intentions. International Journal of Retail \& Distribution Management, 44(8), 860-880. https://doi.org/10.1108/IJRDM-10-2015-0157

Smith, R. A. (1991). The effects of visual and verbal advertising information on consumers' inferences. Journal of Advertising, 20(4), 13-24. https://doi.org/10.1080/00913367.1991.10673351

Sojka, J. Z., \& Giese, J. L. (2001). The influence of personality traits on the processing of visual and verbal information. Marketing Letters, 12(1), 91-106. https://doi.org/10.1023/A:1008132422468

Song, J., Han, K., Lee, D., \& Kim, S. W. (2018). “Is a picture really worth a thousand words?”. A case study on classifying user attributes on Instagram. PloS one, 13(10), e0204938. https://doi.org/10.1371/journal.pone.0204938

Vander Schee, B. A., Peltier, J., \& Dahl, A. J. (2020). Antecedent consumer factors, consequential branding outcomes and measures of online consumer engagement: Current research and future directions. Journal of Research in Interactive Marketing 14(2), 239-268. https://doi.org/10.1108/JRIM-01-2020-0010

Van Esch, P., Heller, J., \& Northey, G. (2019). The effects of inner packaging color on the desirability of food. Journal of Retailing and Consumer Services, 50, 94-102. https://doi.org/10.1016/j.jretconser.2019.05.003

Visentin, M., \& Tuan, A. (2021). Book belly band as a visual cue: Assessing its impact on consumers' in-store responses. Journal of Retailing and Consumer Services, 59, 102359. https://doi.org/10.1016/j.jretconser.2020.102359

Wutich, A., Beresford, M., SturtzSreetharan, C., Brewis, A., Trainer, S., \& Hardin, J. (2021). Meta theme analysis: A qualitative method for cross-cultural research. International Journal of Qualitative Methods, 20. https://doi.org/10.1177/16094069211019907

Yıldırım, E., Arslan, Y., \& Barutçu, M. T. (2016). The role of uncertainty avoidance and indulgence as cultural dimensions on online shopping expenditure. Eurasian Business \& Economics Journal, 4(1), 42-51. http://dx.doi.org/10.17740/eas.econ.2016.V4-04

Yoo, J., \& Kim, M. (2014). The effects of online product presentation on consumer responses: A mental imagery perspective. Journal of Business Research, 67(11), 2464-2472. https://doi.org/10.1016/j.jbusres.2014.03.006 
Yu, S., Hudders, L., \& Cauberghe, V. (2018). Selling luxury products online: The effect of a quality label on risk perception, purchase intention and attitude toward the brand. Journal of Electronic Commerce Research, 19(1), 16-35.

Zhou, L., Dai, L., \& Zhang, D. (2007). Online shopping acceptance model - A critical survey of consumer factors in online shopping. Journal of Electronic Commerce Research, 8(1), 41-62.

\section{Appendix}

Operationalization of the constructs

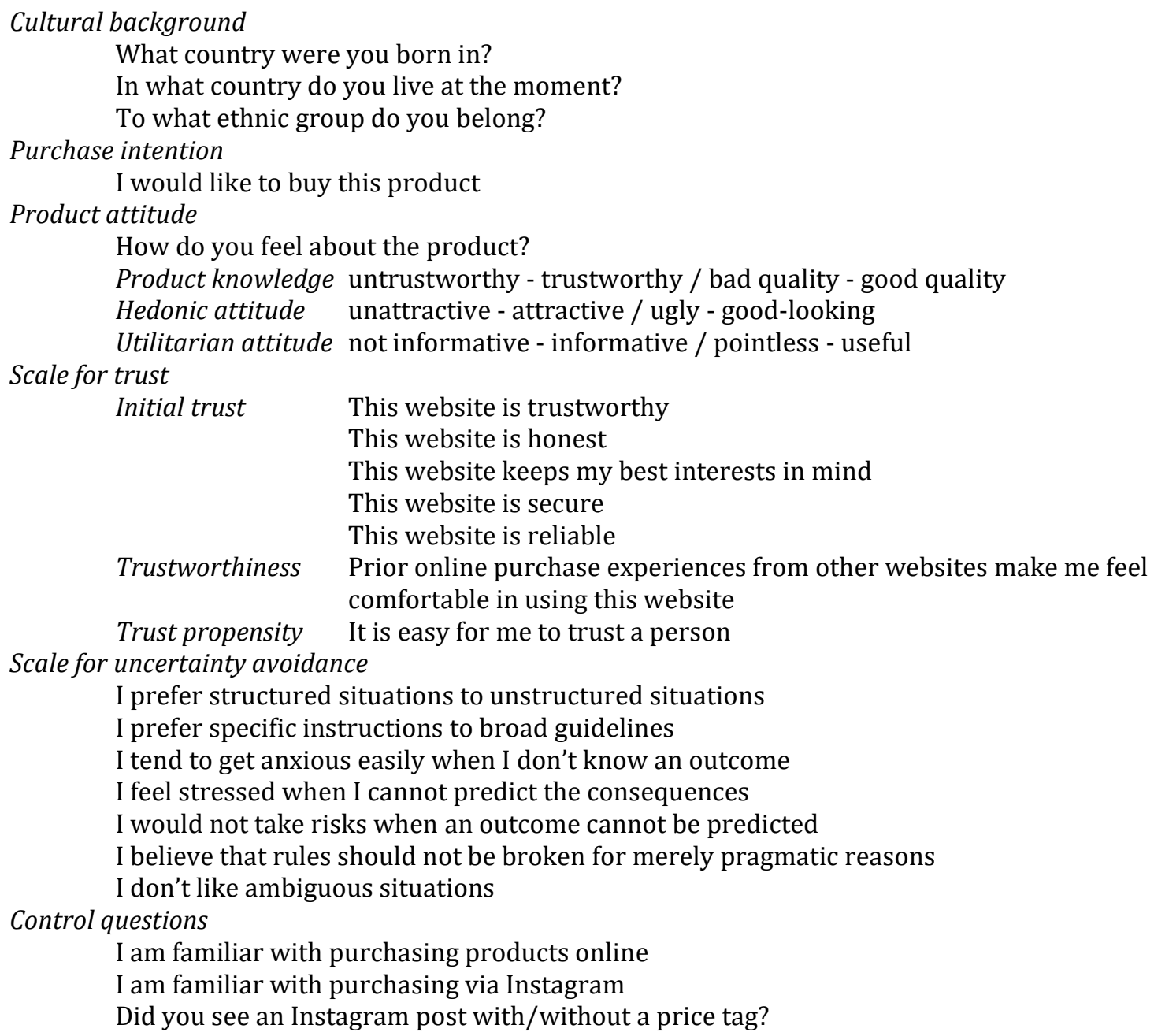

The participants responded to the questionnaire items using a 5-point Likert-type scale (from $1=$ "Completely disagree" to 5 = "Completely agree"). The control questions were answered with a "yes" or "no". 